\title{
An Empirical Analysis on the Influential Elements of the
}

\section{Development of Individual Donation}

\author{
Chao Zhang \\ School of Economics, Southwestern University of Finance and Economics \\ Chengdu 611130, China \\ E-mail: leslie674@gmail.com \\ Nan Zhang \\ School of Economics, Southwestern University of Finance and Economics \\ Chengdu 611130, China \\ E-mail: daojicangsheng@yahoo.com.cn
}

\begin{abstract}
Individual charity is an important way for providing public products and is a significant complement for social guarantee system, which is proved by the snow disaster of China at the beginning of 2008. However, the development of individual charity in China is not promising. At present, there is little exploration on the influential elements of the development of individual donation in China. This paper, from theoretical aspect, analyzes the elements that influence the development of individual donation of China at present stage from the perspectives of supply and need. Further, this paper, based on the investigation data collected in the city of Chengdu, conducts an empirical analysis on the influential elements and comes to meaningful conclusion.
\end{abstract}

Keywords: Individual donation, Influential elements, Section data, Empirical analysis

\section{Introduction}

As a way for individuals to provide public products, charity has been included into the research field of public economics. Donators and charity organizations are usually the research objects of public economics. For one hand, donation is the main source of charity funds and is the base of the development of charity. Foreign economics filed has conducted empirical researches in donation and has established many theories. However, in China, researches on donation are just at their initial stage. For another hand, with the improvement of Chinese economic level, corporation donation gradually draws people's attention. Nevertheless, there is little empirical analysis on individual donation with the background and investigation materials of China as the base. Let us take the US as an example. According to statistics, in the US, above $75 \%$ of the charity funds come from individual donation. Plus inheritance donation, individual donation accounts for more than $80 \%$ in social donation. Seeing from the present situation of China, individual donation accounts for less than $20 \%$. However, with the increase of average individual income and the enlargement of middle class, individual donation may develop towards the main source of charity funds. Therefore, it is necessary to conduct researches on the elements that influence the development of individual donation.

The arrangement of this paper is that part two is the literature review on individual donation and the definitions of issues that this paper focuses on; part three is the theoretical analysis on influential elements of individual donation; part four takes 292 individuals who have made donation as sample and on the basis of questionnaire analysis, examines the concrete influences of income level, tax preference, donation cost, donation return, government expenditure, charity awareness and media propaganda on individual donation expenditure; and part five is about policy connotations.

\section{Literature review and the definitions of issues}

As a behavior choice, to gain return is one of the basic aims of donators. The return includes inner return, fame return, and pure social return. Some scholars believe that the motive for donation mainly comes from the satisfactory feeling brought by the donated money amount, that is, inner return and fame return (Harbaug, 1998). Some do researches on the influence of "thumb a ride" on the donators' gaining of pure social return, that is, the donation of others "squeezes out" the donation willing of the behaviors (Cornes \& Sardlert, 1984).

With regard to donation cost, we can discuss from the following aspects: 
(1) The transparency degree of the charity operation. Bill Harbaugh (1995) thinks that to open the donation to the outside will be active for enhancing the will of individual donation and can enable to decrease the cost of supervision. Robert D. Cooter and Boalt Hall (2003) put forward to make public of donation and suggested to register donation.

(2) The sincerity of the helped in the process of donation. Alberto Alesina and Eliana La Ferrara (2002) found out that the lack of sincerity will bring about the decrease of donation level and the increase of cost.

(3) The diversification of donated objects. The donated objects include time, money, and non-capital objects. Tore Ellingsen and Magnus Johannesson (2007), Lorenzo Cappellari, Paolo Ghinetti and Gilberto Turati (2006) came up with that the effective collocation of donated objects can raise efficiency.

Income level has strong restraint feature (Meier, 2006) and restricts the donation capacity at fundamental level. Schwartz (1968) applied the sum of time series data and examined the income elasticity of donation. He opines that the income elasticity of donation is rather high and is in between 0.53 and 1.34. Nelson and Levy (1970), Shatto (1978), and Clotfelter (1985) came to similar conclusion in their researches. At present, the researches on the influences of tax on corporation donation are plentiful. Navarro (1988) applied section materials and found that with the increase of tax rate, the amount donated by corporations will decrease. The section research of Carroll and Joulfaian (2005) indicates that the price elasticity of donation is negative and remarkable. Boatsman and Gupta (1996) adopted panel date to conduct research and proved that the increase of tax rate will result in the decrease of donation.

Many foreign literatures show that the influence of government on individual donation is intangible. The conclusion of Warr (1982, 1983), "neutral outcome", says that if only the inner Nash equilibrium exists, the influence of government support on individual donation will be neutral. Before Warr, Becker (1974) also came to such conclusion. Subsequently, Barro (1974) proved Becker's conclusion. Kemp (1984) further developed the conclusion of Warr. Blume and Varian (1986), Cornes and Schweinberger (1996), Cornes and Itaya (2003), and Boardwar, Pestieau and Wildsasin (1989) put forward that even if the individual income tax and the subsidy of government to individual donation are distorted, such neutral outcome will still exist. Therefore, it is not sure that whether the influence of government expenditure on individual donation is "squeezing in" or "squeezing out".

Foreign literatures' discussion on charity awareness mainly focuses on religious field (Harbaug, 1998; Gruber and Hungerman, 2006) and is about the correlation between charity awareness and religious beliefs. Philip H. Brown and Jessica H. Minty (2006) prove that, based on the empirical data collected from the donation for the tsunami of 2004, to increase the propaganda frequency of media will powerfully advance internet donation.

\section{Analysis on the influential elements}

\subsection{Influential elements of the supply of individual donation}

Income level is an important element in influencing individual donation. According to the need-hierarchy theory of Maslow, the need-hierarchy of human beings improves with the increase of incomes. It is commonly agreed that the need of individual donation is spiritual need of high-hierarchy. According to such reference, for one hand, individual donation can be considered as spiritual consumption of individuals. The same as other consumption behaviors, donation is the increasing function of income and is restricted by incomes; for another hand, the spiritual consumption which is of high-hierarchy, is a luxury, is of rather high income need elasticity, and is under significant influence of income level.

Donation cost refers to the entire cost incurred by a donator in donation, such as search cost and supervision cost. To put it simple, the donation cost is the transaction cost of donation. This paper considers donation as a consumption of spiritual products of an individual or family. Although donation is different from other common spiritual products, it is still a consumption behavior. We can probe into the relationship between donation cost and donation behavior.

Tax influences donation by two means. One is to decrease donation cost through making out of targeted tax incentives, that is, replacement effect. For example, deduction before tax can decrease the tax cost of the donators; the set-up of property transfer tax and the set-up of inheritance tax can transfer cost though increasing capitals and thus decrease the donation cost comparatively. The two ways will stimulate individuals to increase donation. The other is income effect, which indirectly limits individual donation by way of controlling the disposable capital after tax through the fixing of tax rate. For example, the entire tax rate can be decreased; as a result, the disposable capital after tax is increased and the donation can be increased too. The first system has been commonly recognized and has become a policy system on donation of many states.

Donation return is also an important element in influencing individual donation. Donation return includes inner return, fame return and pure social return and is represented by way of donation behaviors. Due to the difference of individual preference, different return type weights differently in the decision-making systems of donators. Hence, their influence on donation behaviors and donation amount varies. The special groups with high incomes, such as millionaires and stars, mainly care about their fame returns; hence, the fame element weights greatly in their decision-making system on donation. The Hurun charity hit parade is an example. However, the starting point of some religious men or men with 
"the sense of sin" may be that they pursue inner balance rather than social fame. Similarly, people who care about public interest and are of "citizen awareness" may care more about pure social returns.

Charity awareness plays positive influence on donation. Donation is an economic behavior and is more a social behavior. Donators are encouraged by economic benefits and are influenced by cultural awareness. The non-compulsory nature and voluntariness of charity requires that the development of charity must be in a social environment full of love and care. It requires donators to have willing-to-help morality, humanism-care value view and behavior modes, and strong charity awareness. Religious motives, social and culture motives and morality motives will all exert influence on the formation and cultivation of charity awareness.

\subsection{Influential elements of the need of individual donation}

Elements discussed above start from the perspective of individual donation scale influenced by suppliers. Besides, there are some elements that influence donation from the angle of donation need. The final scale of donation is determined by individual's willingness to "supply" donation and the need of society on donation. Generally speaking, the need of society on donation far exceeds the supply. Hence, the determinant elements usually come from the suppliers. However, for certain donators, the donation need will sometimes play important role.

Most of the donation ultimately goes to the field of environment, education and other public careers. Part of the reason is that those fields lay strong need for donation funds. For example, the proportion of population receiving education accounts for a relatively large part of the entire population. Therefore, education institutions need more capital resources. Under the circumstance when other elements are fixed, the pretty high proportion of population receiving education and population supported by the lowest guarantee will result in rather high donation needs.

The occurrence of some special events would rapidly raise the need on donation in short period, such as flood, tsunami and other natural disasters that can result in substantive losses. In 1998, many areas of China were flooded severely. The donation amount in 1998 far exceeds other neighboring years. In 2006, Chongqing was hit by severe draught. The capital donation received by Chongqing in 2006 is nearly twice that received by Chongqing in 1998 for the flooding disaster. Liming Pan (2005) analyzed the relationship between social donation amount of China and the direct economy loss incurred from natural disasters covering from 1996 to 2002 and found that the social donation of China is of evident need-pushing effect.

\subsection{Government expenditure and media propaganda: both influence the need and supply of donation}

The influence of government expenditure on individual donation is complicated. First of all, from the perspective of donation need, the increase of government expenditure on charity affairs will replace individual donation and squeeze out individual donation. Besides, some researches have proved that government, donators and charity organizations are of the same strategy mutual-active environment. Charity organizations have changed from inactive waiting to actively gathering funds. The donated amount is directly influenced by the endeavor of charity organizations. When government increases its capital support to certain charity career, the charity organization will cut down their endeavor. Hence, the government expenditure squeezes out "the endeavor for donation" rather than donation and results in the decrease of individual donation. However, if the government expenditure on charity organization requires individual donation to go with, the individual donation may be "squeezed in" and form the "complement" nature. Secondly, government expenditure will influence donation by way of supply, which may either "squeeze in" or "squeeze out" individual donation. For one hand, the support of government on charity organizations will cause the charity organizations to lose fork independence. The potential donators will doubt the pureness of the fork organizations and their willingness to donate are hence lowered. For another hand, government expenditure can be viewed as the signal of the "quality" of the charity organizations and hence, decrease the search and supervision cost of potential donators. At the same time, government expenditure can generate example effect for individual donation and is beneficial to raising the confidence of donators.

Media propaganda is mostly considered as an element that influences supply, that is, the charitable propaganda of Medias can be viewed as a method to improve supply level. However, from the perspective of the condition of China, it is known that the religious tradition is not remarkable and the development of charity organizations and funds lag behind; therefore, media propaganda can be seen as the element that influences both supply and need. For one aspect, to propaganda traditional morality and social climate can help to popularize charity awareness and get forward charitable donation. For another, to publish the information of the helped and areas received giving and to form overwhelming media calling will bring about direct need of individual donation.

\section{Date description and empirical analysis}

\subsection{Date sources}

The nine districts of Chengdu are the areas investigated of this paper. 980 questionnaires were given out and 947 were collected, of which 826 are valid. 352 individuals (or their family members) have made donation, accounting for $42.6 \%$. 
60 donators earn less than RMB1600 per month. Because the important element, tax preference, cannot be analyzed (in China, one who earns less than RMB1600 does not pay any tax), the 60 donators will not be included into the analysis. The investigation is retrospective and the data collected are about individual annual donation of 2006, of which the data on government budget and population proportion are from the year book 2007 of Chengdu. The data are section data.

\subsection{Definitions of variables}

(1) Donation expenditure: regressive dependant variable. The information of donators, including the donation of objects and labor, are collected through questionnaires. Capital is the final statistical method (labor is converted into capital by capital/labor). RMB is the unit.

(2) Income level: the income of individual is the budget restraint of individual donation. This paper adopts the result of questionnaire investigation and takes the pre-tax income of the investigated as the index and RMB as the unit.

(3) Donation cost: according to the types of costs, the donation cost can by divided into the cost for searching for donation information, the cost for analyzing the future of charity programs, the cost for selecting proper donation forms, the cost for donation behavior, and the cost for supervision. This paper describes donation cost by setting up virtual variables.

(4) Tax preference: for individuals, donation fields vary with each other in the algorithm of tax preference. For the convenience of statistics, this paper uniformly adopts $30 \%$ as the tax rate for the tax amount that enjoys donation preference. From the actual investigation results, it can be seen that the donation amount is basically within $30 \%$. Therefore, the calculation formula for tax preference is:

Tax $=($ individual income -1600$) *$ progressive tax $-($ individual income $-1600-$ donated amount $) *$ progressive tax

(5) Donation awareness: this paper adopts the education background of donators as index and converts the education background into the education receiving years of the investigated. The data information comes form the questionnaires. Although it is not so comprehensive to use education receiving years as index for charity awareness, it still represents the charity awareness.

(6) Government expenditure: data are from the government budget of the districts of Chengdu, including expenditure on education and social guarantee funds. The government expenditure is measured by the individual average of the sum of the two items. RMB is the unit.

(7) Media propaganda: TV Medias of the main stream are the statistic focus. The time of the investigated spent in watching the news and consultation and information TV programs is taken as the measurement and minute is the unit.

(8) The proportion of students at campus and people receiving the lowest guarantee: the two indexes are used to express the donation need. The higher the proportion is, the greater the donation need is. This paper applies the number of students and population receiving the lowest guarantee of Chongqing in 2006.

\subsection{Description of the statistics}

The average donation amount of the sampled individual is RMB191.7637, of which the highest individual donation is RMB1, 500 and the lowest is RMB5. The donation expenditure is annual expenditure. The average before tax income of the sample group of year 2006 is RMB3,257.397. The average tax preference is RMB26.9392. The average donation cost is RMB1.7295, which is calculated by adding the virtual variables. The charity awareness is measured by the years receiving education covering from 0 to 18 and the average value is 15 , which shows that the education degree of the sample group is rather high. Correspondently, the media propaganda is measured by the time spent in watching news or consultation and information programs and covering from 0 to 180 and the average value is 80 minutes. In addition, the average government expenditure in the 9 districts is RMB561.6078. However, the difference is kind of huge. The standard deviation reaches 8.8949 and the difference between the highest and the lowest is RMB531. The proportion of students and the population receiving the lowest life guarantee of the 9 districts vary slightly, whose average value are respectively 0.1219 and 0.0162 . Their fluctuation ranges are respectively between 0.09000 and 0.1489 and between 0.0075 and 0.0212

\subsection{Regressive results and analysis}

Based on the aforesaid analysis, this paper chooses the following regressive equation:

$$
\text { Giving }_{i}=\beta_{0}+\beta_{1} \text { income }_{i}+\beta_{2} \sum_{j=1}^{5} r_{j} \text { givingprice }_{j i}+\beta_{3} \text { tax }_{i}+\beta_{4} \text { sense }_{i}+\beta_{5} \text { budget }_{i}+\beta_{6} \text { media }_{i}+\beta_{7} \text { education }_{i}+\beta_{8} \text { poor }_{i}+u_{i}
$$

The common matlab is adopted to conduct estimation. Because there may exist in the sample data multicollinearity and heteroskedasticity, three regressions are made (regression forward). Since the data are section data, in the regressions, covariance matrix that is consistent with heteroskedasticity autocorrelation is adopted to rectify the heteroskedasticity and autocorrelation whose form is unknown (the HAC estimation is obtained through newey-west). The following table 
reports the regressive reports of the equation.

Regressive Results

\begin{tabular}{|c|c|c|c|c|c|c|}
\hline \multicolumn{7}{|c|}{ Dependant variables: giving 292 observed values } \\
\hline \multirow[b]{2}{*}{$\begin{array}{l}\text { Independent } \\
\text { variables }\end{array}$} & \multicolumn{2}{|c|}{ Regression No. 1} & \multicolumn{2}{|c|}{ Regression No.2 } & \multicolumn{2}{|c|}{ Regression No.3 } \\
\hline & $\begin{array}{l}\text { Estimated } \\
\text { coefficient } \\
\text { value }\end{array}$ & T value & $\begin{array}{l}\text { Estimated } \\
\text { coefficient } \\
\text { value }\end{array}$ & T value & $\begin{array}{l}\text { Estimated } \\
\text { coefficient } \\
\text { value }\end{array}$ & T value \\
\hline Income & 0.0130 & 4.1308 & 0.0156 & 5.1500 & 0.0156 & 5.1619 \\
\hline Giving price & -11.1714 & -6.1141 & -11.8045 & -6.4334 & -11.7926 & -6.4405 \\
\hline Tax & 4.5211 & 45.8470 & 4.4552 & 45.9680 & 4.4549 & 46.0470 \\
\hline Sense & 2.2850 & 0.1277 & & & & \\
\hline Budget & -0.0054 & -0.5256 & -0.0044 & -0.4278 & -0.0042 & -0.4128 \\
\hline Media & 0.0063 & 0.0973 & 0.0763 & 1.2673 & 0.0766 & $1.2842^{*}$ \\
\hline Education & 57.9038 & 0.4816 & 26.3399 & 0.2174 & & \\
\hline Poor & 411.6159 & $1.3108^{*}$ & 333.7253 & 1.1117 & 264.2986 & $1.3223^{*}$ \\
\hline R-squared & \multicolumn{2}{|l|}{0.4964} & \multicolumn{2}{|l|}{0.4944} & \multicolumn{2}{|l|}{0.4944} \\
\hline Adjusted $\mathrm{R}^{2}$ & \multicolumn{2}{|l|}{0.4804} & \multicolumn{2}{|l|}{0.4780} & \multicolumn{2}{|l|}{0.4780} \\
\hline
\end{tabular}

Note: * means that the markedness level is remarkable below $20 \%$; the default markedness level is $5 \%$.

Regression No.1 includes all the explanation variables in the basic equation. Its results show that income level, donation cost, tax preference and charity awareness exert remarkable influence on individual donation expenditure, whilst government expenditure, media propaganda, and the proportions of students and the population receiving the lowest life guarantee just exert slight influence on individual donation. Because there is evident linear correlation between charity awareness and individual income level, regression No.2 excludes charity awareness. The results of regression No.2 show that the influence of government expenditure, media propaganda, and the proportions of students and the population receiving the lowest life guarantee on individual donation expenditure is still not remarkable. However, the influence of media propaganda is evidently increased. As the $t$ value of the proportion of students fluctuates the most, in order to further examine the influence of media propaganda on individual donation expenditure, regression No.3 excludes the proportion of students (whose $t$ value is too low) and focuses on the influence of income level, donation cost, tax preference, government expenditure, media propaganda and the proportion of the population receiving the lowest life guarantee on individual donation expenditure. The results of regression No.3 indicate that except government expenditure, the statistical influence of other variables on individual donation amount is remarkable. What is more, the goodness of fit is slightly changed compared with regression No.1 and No.2 and is rather fine.

The final regressive results of this paper are:

$$
\begin{gathered}
\hat{\text { Giving }}=33.2842+0.0156 \text { income }-11.7926 \sum_{j=1}^{5} r_{j} \text { givingprice }{ }_{j}+4.4549 \text { tax } \\
\begin{array}{ccc}
(2.3896) \quad(5.1619) & (-6.4405) & (46.0470) \\
-0.0042 \text { budget }+0.0766 \text { media } & +264.2986 \text { poor }
\end{array} \\
(-0.4128) \quad(1.2842) \quad(1.3223) \\
\text { Adjusted } \mathrm{R}^{2}=0.4780, \text { D.W. }=2.116, \mathrm{~F}=46.4478
\end{gathered}
$$

Seeing from the final results, individual donation expenditure is of remarkable positive correlation with individual income, which means that the adding of 1unit of individual income brings about the increase of 0.0156 unit of donation. This result is similar to the research result of Stephan Meier (2006). However, the research of this paper is different from that of Stephan Meier in that the income restraint strength is lower than Stephan's result - the income elasticity is rather low, which might result from the random nature of individual donation in China.

Individual donation is of remarkable negative correlation with donation cost. The higher the donation cost is, the lower the individual donation is. What is more, the estimated coefficient value is rather high, which indicates that because of the problems existing in donation channels, charity operation system and sincerity awareness, the transaction cost in the process of donation is rather high which severely influences the development of individual donation. With the development of market economy, people gradually become aware of cost. So do people in making donation. They will 
not spend too much time and energy to conduct charity donation.

Individual donation is of high positive correlation with tax preference. The regressive estimated value of coefficient is 4.4549 and is remarkable in statistical perspective. The common explanation for it is that tax preference positively bestirs individual donation. The policy to deduct before tax of the individual income tax directs obviously on donation, which is also similar to the previous researches. The difference is that the estimated regressive coefficient of this paper is very high, which shows that the signal function of tax preference policy (the encouragement and support on individual donation) is very evident. Because individual profits are directly involved, tax sensitivity of individual donation is far higher than that of cooperation donation.

The results of the three regressions cannot reflect the relationship between government expenditure and individual donation. The estimated values of coefficient are very small and are not remarkable in statistical perspective. Therefore, it can be drawn that government expenditure does not have obvious influence on individual donation. This paper, with the detailed data collected from China, proves the "neutral outcome" raised by Warr (1981, 1983). As stated in the above, it is not certain whether government expenditure "squeezes out" or "squeezes in" individual donation and it is determined by the mutual action degree of the two.

Empirical researches abroad (Philip H. Brown \& Jessica H. Minty, 2006) show that media propaganda and individual donation amount is of rather obvious positive correlation. However, the results of regression No.1 indicate that such correlation is not remarkable. Be excluding variables, the results of regression No.1 and No.2 show that the correlation between media propaganda and individual donation is remarkable when the markedness level is below $20 \%$. Generally speaking, China, as a whole, lacks religious tradition and the development of charity organizations and funds lag behind; hence, media propaganda should have wide influence on individual donation. However, the regressions indicate that the correlation is not obvious, which reflects the defect of this paper, that is, to take place of media propaganda with the time of the investigated spent on watching news and consultation and information programs. Experiences show that Medias propaganda charity mainly through news and consultation and information programs (some through commonweal advertisement). Hence, the time the investigated spent on watching those programs is of representative nature. However, seeing from the current situation of China, charity propaganda just accounts for a small portion in the broadcasting of news and consultation and information programs. What is more, the programs and channels that broadcast charity propaganda is not flexible, which, to great extent, weakens the influence of media propaganda on individual donation.

Individual donation amount is influenced by the proportion of people receiving the lowest life guarantee (the markedness level is remarkable below 20\%; actually, the markedness level is close to 10\%) and the estimated coefficient is pretty high, which shows that the population receiving the lowest life guarantee strongly pushes individual donation. The influence of the proportion of students on individual donation shown by both regression No.1 and No. 2 is not remarkable, which to great extent results from the overflowing nature of donation. It can be found from the sample data that the average income is rather high in districts where the student proportion is low; where the student proportion is high, the average income is low. The districts where average income is high may not have many schools because of their high land values, which causes that their donation flow may generate overflowing effect and results in the unremarkable correlation between the two.

As a whole, the influential elements from supply aspect, such as income, tax preference and donation cost, exert much more remarkable influence that those from the need aspect, which is consistent with the actuality of individual donation in China at present, that is, the need of individual donation far exceeds its supply. Therefore, the elements of supply shall hold the dominant position in individual donation.

\section{Policy connotations}

In countries where charity is developed, charity organizations and fund associations are particularly engaged in charity and are in charge of the use of donated funds. Such concept is widely recognized in the entire society. Donators only need to send the donated objects to the charity organizations. However, in China, the recognizing of charity organizations is not so optimistic. Donators have not yet formed the concept of "donation-charity organizations'.

Although it is hard to gauge the donation returns, the use compensation of donation for donators cannot be denied. Therefore, it is necessary to set up a sustainable incentive system to strengthen the fame return of donation. The occurrence of Hurun charity hit parade brings about a group of new charitarians in China. However, Hurun charity hit parade just focuses on millionaires. What is more important is to encourage people with common income to actively participate in donation. We can set up "China charity dictionary" or register the donation information of donators through website publication and coordinate information collection organs to raise donators' credit class.

Tax preference is controllable. The increase of income will of course raise the charity donation capacity of people. Hence, to raise tax preference of donators will help to enlarge the scale of individual donation. Governments should raise tax preference through increasing the tax exemption rate and realize that the donation expenditure of donators 
comes from the tax that should be paid so as to demonstrate positive policy guide. We can also improve the donation cost from various aspects that constitute of the cost. The donation forms shall be diversified and the non-capital donation forms, such as free labor and the donation of second hand objects, shall be encouraged. We can widen the donation channels by way of setting up community love supermarkets and initiating internet donation. For the supervision cost, we should emphasize on enforcing the legislative supervision on charity organizations and establishing transparent supervision system. We can also set up valuable charity projects, such as education of poor areas, helping the poor, social commonweal programs, health, entironment, Olympic projects, and emergency system guarantee for sudden public health incidents, to raise the recognizing degree of potential donators and attract charity funds.

To cultivate and heighten charity awareness is beneficial to advancing individual donation. However, the aforementioned donation behaviors established on the morality basis are not inner responsibility behaviors, which lack systematic and standard operation system and are not sustainable. At present, China is at the transformation period towards modern society. Individuals of China have not yet formed integrated right and obligation concept and are not aware of that donation is a responsibility that a citizen shall bear for the society. Seeing from long term, the long lasting development of donation behaviors shall depend on the popularization of citizen awareness, the establishment of obligation concept, and the enforcement of the construction of donation system.

\section{References}

Alesina, Alberto and La Ferrara, Eliana. (2002).Who trusts others? Journal of Public Economics, Volume 85, Issue 2, pp. 207-234.

Andreoni, James. (1990).Impure altruism and donations to public goods: a theory of warm-glow giving. The Economic Journal, Volume 100, Issue 401, pp.464-477.

Bradley, Ralph, Holden, Steven and McClell, Robert. (1999). A robust estimation of the effects of taxation on charitable contributions. Journal of Public Economics.

Cappellari, Lorenzo, Ghinetti, Paolo and Turati, Gilberto. (2006).On time and money donations. Journal of Public Economics, November10.

Davidson, William. (2006). Media coverage and charitable giving after the 2004 tsunami. Institute Working Paper, No.855, December.

Edlin, AaronS. (2005).The Choose-your-Charity tax: a way to incentivize greater giving. The Economists' Voice, Volume 2, Issue 3.

Harbaugh,William T. (1998).The prestige motive for making charitable transfers. American Economic Review, 88:2,277-282.

Navarro P. (1988). Why do corporations give to charity? Journal of Business, 61:65-94.

Pan, Liming. (2005). Research on Public Object Market and Voluntary Supply of China. Shanghai: Shanghai People's Press.

Ribar, David and Wilhelm, Mark. (2002). Altruistic and joy-of-giving motivations in charitable behavior. Journal of Political Economy, Vol. 110, April.

Schwartz, R.A. (1968). Corporate philanthropic contributions. Journal of Finance, 23:479-97.

Zhang, Xin, Cao, Hongbin and Shi, Wenpo. (2006). Empirical research on corporation donation of China. Thesis paper published at the sixth Chinese Economics Annual Conference. 